\title{
Environmental impacts of local food production in Japan and changes needed for future sustainability
}

\author{
S. Mishima \& K. Kohyama \\ National Institute for Agro-Environmental Sciences, Japan
}

\begin{abstract}
We employed the distance-to-target method to devise a single environmental impact indicator $(E I I)$ of the total environmental impact of agricultural production, mainly fertilizer use. We focused on the effects of fertilization on greenhouse gas (nitrous oxide, $\mathrm{N}_{2} \mathrm{O}$ ) emission, groundwater pollution by nitrogen $(\mathrm{N})$ through leaching and surface (river) water eutrophication by $\mathrm{N}$ and phosphorus $(\mathrm{P})$ through erosion as environmental impacts in the base year of 1990 as well as in 2005. We estimated each environmental impact in all (47) prefectures and at the Japanese national scale as a reference value. Target values were set temporally, except $\mathrm{N}_{2} \mathrm{O}$ emission, which has a midterm governmental target. The EII in each prefecture in 1990 and 2005 was calculated from normalized environmental impacts and weighting factors using reference and target values. The EII in each prefecture ranged from 0.9 to 81.1 in 1990 and from 0.7 to 68.4 in 2005 . Surface water eutrophication by $\mathrm{N}$ and P contributed greatly to the $E I I$, especially in prefectures with high $E I I$ values. To mitigate high $E I I$ values, the agricultural sector should reduce the $\mathrm{N}$ surplus by decreasing the fertilizer input and fertilizing with $\mathrm{P}$ dependent on soil $\mathrm{P}$ fertility to prevent excessive accumulation of $\mathrm{P}$.
\end{abstract}

Keywords: distance-to-target method, environmental impact indicator, fertilization, prefectural scale.

\section{Introduction}

Although fertilization is essential for agricultural production, it causes various negative environmental impacts, such as greenhouse gas emissions, eutrophication and pollution of surface and groundwater. Previous studies have 
considered these problems individually, but it is important to examine the total environmental impact of fertilizer use to evaluate the optimal conditions of agricultural production by life cycle assessment (LCA). The distance-to-target (DtT) method [1] is sometimes used in LCA to simplify the total environmental impact consisting of various kinds of impacts.

In this study, we estimated nitrous oxide $\left(\mathrm{N}_{2} \mathrm{O}\right)$ emission due to agricultural production, potential groundwater pollution by nitrogen $(\mathrm{N})$ due to surplus $\mathrm{N}$ from agricultural production and potential surface water eutrophication by $\mathrm{N}$ and phosphorus (P) due to farmland soil erosion in 1990 and 2005 for the 47 prefectures of Japan. We then aggregated these four impacts into one indicator value as an environmental impact indicator (EII) using the DtT method. We evaluated the relative environmental impact due to prefectural agricultural production by comparing EII values among prefectures and between the two years. In addition, we analyzed what factors may have caused high or low EII values in particular prefectures.

\section{Materials and methods}

\subsection{Data sources}

The amounts of $\mathrm{N}$ and $\mathrm{P}$ flow associated with agricultural production in the 47 prefectures and in Japan as a whole were those reported by Mishima and Kohyama [2]. Soil fertility data were taken from MAFF [3].

\subsection{Nitrous oxide emission}

Nitrous oxide emission was estimated by IPCC Tier 2 methodology [4]; namely, $\mathrm{N}_{2} \mathrm{O}$ emission was calculated as $\mathrm{N}$ flows multiplied by emission factors of the various model components. This study included direct $\mathrm{N}_{2} \mathrm{O}$ emission from livestock waste processing and fertilization of farmland soil and indirect $\mathrm{N}_{2} \mathrm{O}$ emission through leaching and deposition of $\mathrm{N}$.

\subsection{Groundwater pollution potential}

The potential groundwater pollution by $\mathrm{N}(G W)$ was calculated based on residual $\mathrm{N}$ in agricultural production $(R N)$, precipitation (Prec) and the potential evapotranspiration (ET) from Mishima et al. [5], using eqn (1):

$$
G W=R N /(\text { Prec. }-E T)
$$

\subsection{Surface water eutrophication potential}

The potential surface water eutrophication by $\mathrm{N}$ and $\mathrm{P}$ due to erosion $(E N, E P)$ at the watershed and prefecture scales were estimated based on the erosion 
potential $(E)$ calculated using the USLE, residual $\mathrm{N}$ and $\mathrm{P}(R N, R P)$ and available $\mathrm{N}$ and $\mathrm{P}$ in farmland soil $(A N, A P)$, as follows:

$$
\begin{aligned}
& E N=(R N+A N) \times E \\
& E P=(R P+A P) \times E .
\end{aligned}
$$

\subsection{Target setting}

The Japanese government set as a midterm target a $25 \%$ reduction of total greenhouse gas emissions by 2025 as compared to 1990 levels. Therefore, we used a $25 \%$ reduction of $\mathrm{N}_{2} \mathrm{O}$ emission versus the level in 1990 as the anticipated target.

In contrast, no governmental or regulatory targets have been set for reductions in groundwater pollution and river water eutrophication. Therefore, we set tentative targets based on the inverse of the regression reported by Mishima et al. [5], which is the correlation between groundwater pollution potential and the percentage of observation wells in prefectures that exceeded the water quality standard $\left(10 \mathrm{mg} \mathrm{N} \mathrm{L}^{-1}\right)$ :

$$
E O W=0.606+(0.634 \times G W)
$$

where $E O W$ is the percentage of observation wells in prefectures that exceeded the water quality standard. The target groundwater pollution potential was set such that all observation wells would meet the water quality standard.

For the surface (river) water eutrophication potential, $2 \mathrm{mg} \mathrm{N} \mathrm{l}^{-1}$ and $0.1 \mathrm{mg} \mathrm{P}$ $1^{-1}$ were employed as tentative targets [6]. At river water-quality monitoring points $(n=1260)$ set at the output of each watershed, first the correlations between total $\mathrm{N}$ and $\mathrm{P}$ flow and $E N$ and $E P$, respectively, were tested. Then we calculated the total $\mathrm{N}$ and $\mathrm{P}$ flows necessary for $\mathrm{N}$ and $\mathrm{P}$ concentrations to meet our tentative standards and tested the correlations of these flows with $E N, T N$ ', $T P^{\prime}$ and $E P$.

\subsection{Application of the DtT method for aggregation}

According to Brentrup et al. [7], impacts were normalized, weighted and then aggregated using eqn (5):

$$
E I I=\sum_{i}\left(w_{i} \times \frac{I_{i}}{N_{i}}\right),
$$

where $I_{i}$ is the impact indicator for impact category $i, N_{i}$ is the normalization reference (national average in this study) for impact category $i, w_{i}$ is the weighting factor for impact category $i$ and $w_{i}$ is set as follows:

$$
w_{i}=\frac{P_{i}}{T_{i}},
$$


where $P_{i}$ is the present normalization reference of impact category $i$ and $T_{i}$ is the target reference of impact $i$. Here $i$ represents $\mathrm{N}_{2} \mathrm{O}$ emission, groundwater pollution potential by $\mathrm{N}$ or surface water eutrophication potential by $\mathrm{N}$ and $\mathrm{P}$. The baseline year was set to 1990 .

\section{Results and discussion}

\subsection{Environmental impacts}

\subsubsection{Nitrous oxide emission}

National $\mathrm{N}_{2} \mathrm{O}$ emission levels in 1990 and 2005 were 4.45 and $3.84 \mathrm{~kg} \mathrm{~N} \mathrm{~N}_{2} \mathrm{O}-\mathrm{N}$ $\mathrm{ha}^{-1}$, respectively. The main causes of the reduction in $\mathrm{N}_{2} \mathrm{O}$ emission were the reductions in chemical $\mathrm{N}$ fertilizer application from 116.4 to $91.9 \mathrm{~kg} \mathrm{~N} \mathrm{ha}^{-1}$ and in livestock waste production from 148.3 to $145.6 \mathrm{~kg} \mathrm{~N} \mathrm{ha}^{-1}$. In both years, the highest $\mathrm{N}_{2} \mathrm{O}$ emission was observed in Shizuoka, followed by Miyazaki and Kagoshima. Among all prefectures, Shizuoka has the largest area of tea plantations, which receive the highest chemical $\mathrm{N}$ fertilizer input [8] and have the highest emission factor (2.62) [9] among all crops. Miyazaki and Kagoshima are prefectures with intensive livestock farming, which is a major source of $\mathrm{N}_{2} \mathrm{O}$ emission in Japan. The lowest $\mathrm{N}_{2} \mathrm{O}$ emission levels were in Fukui and Ishikawa, which both have extensive livestock farming and rice paddy farming that receive the lowest chemical $\mathrm{N}$ fertilizer [8] and that has the lowest emission factor (0.31) among crops [9].

\subsubsection{Groundwater pollution potential}

The national average groundwater pollution potential was $5.36 \mathrm{mg} \mathrm{N} \mathrm{l}^{-1}$ in 1990 and $4.06 \mathrm{mg} \mathrm{N}^{-1}$ in 2005. The highest values were observed in Kagawa (26.21 $\mathrm{mg} \mathrm{N}^{-1}$ in 1990 and $25.11 \mathrm{mg} \mathrm{N}^{-1}$ in 2005), because of high livestock waste production caused by the most intensive poultry farming, as well as the lowest $($ Prec $-E T)$ value $(569 \mathrm{~mm})$ in Japan. Kumazawa [10] reported that groundwater pollution by $\mathrm{N}$ tends to occur in intensive livestock and upland farming areas rather than in paddy farming areas. According to our estimates, however, Miyazaki, the prefecture with the most intensive livestock farming, and Kagoshima, that with the second most intensive, did not have high groundwater pollution potential, because of large (Prec - ET) values. The Kanto region (around the Tokyo metropolitan area) had a relatively high groundwater pollution potential, although the reasons are unclear.

\subsubsection{Surface water eutrophication potential}

The national average surface water eutrophication potential values were $10.3 \mathrm{~kg}$ $\mathrm{N} \mathrm{ha}^{-1}$ and $4.7 \mathrm{~kg} \mathrm{P} \mathrm{ha}^{-1}$ in 1990 and $5.1 \mathrm{~kg} \mathrm{~N} \mathrm{ha}^{-1}$ and $8.9 \mathrm{~kg} \mathrm{P} \mathrm{ha}^{-1}$ in 2005. Shizuoka had the highest values for both $\mathrm{N}$ and $\mathrm{P}\left(161.6 \mathrm{~kg} \mathrm{~N} \mathrm{ha}^{-1}\right.$ and $69.7 \mathrm{~kg} \mathrm{P}$ $\mathrm{ha}^{-1}$ in 2005), followed by Aichi (135.7 kg N ha $\mathrm{kg}^{-1}$ and $56.5 \mathrm{~kg} \mathrm{P} \mathrm{ha}^{-1}$ in 2005) and Okinawa (115.0 kg N ha $\mathrm{kn}^{-1}$ and $51.3 \mathrm{~kg} \mathrm{P} \mathrm{ha}^{-1}$ in 2005). The lowest values were in Shiga (0.018 kg N ha ${ }^{-1}$ and $0.007 \mathrm{~kg} \mathrm{P} \mathrm{ha}^{-1}$ in 2005). This environmental impact was largely dependent on erosion potential. In general, prefectures in the south- 
west of Japan or on the Pacific Ocean side had higher surface water eutrophication potential than prefectures in the north-east or on the Japanese Sea side. In addition, prefectures dominated by paddy rice farming had lower values than those dominated by upland crops or orchards.

\subsection{Weighting factors and aggregated indicator}

\subsubsection{Nitrous oxide emission}

The weighting factor for $\mathrm{N}_{2} \mathrm{O}$ emission was $1.33(=100 / 75)$, because $25 \%$ cut is governmental direction.

\subsubsection{Groundwater pollution potential}

The regression equation between the percentage of observation wells in prefectures that exceeded the water quality standard and potential groundwater pollution by $\mathrm{N}$ was as follows:

$$
G W=5.42+(0.52 \times E O W)(r=0.563, p<0.001)
$$

Therefore $5.42 \mathrm{mg} \mathrm{N}^{-1}$ was the designated value. The weighting factor for groundwater pollution potential was $0.992(=5.38 / 5.42$; national average is 5.38$)$.

\subsubsection{Surface (river) water eutrophication potential}

The regression formulas were as follows:

$$
\begin{array}{ll}
T N=4.033+(0.867 \times E N) & (r=0.522, p<0.001) \\
T N^{\prime}=5.099+(0.592 \times E N) & (r=0.343, p<0.001) \\
T P=0.265+(0.0609 \times E P) & (r=0.481, p<0.001) \\
T P^{\prime}=0.259+(0.0372 \times E P) & (r=0.337, p<0.001),
\end{array}
$$

where $T N$ and $T P$ are total $\mathrm{N}$ and $\mathrm{P}$ flows $(\mathrm{Mg})$ at real water-quality monitoring points. $T N^{\prime}$ and $T P^{\prime}$ are temporal $\mathrm{N}$ and $\mathrm{P}$ flows when water-quality targets are set as $2 \mathrm{mg} \mathrm{N}^{-1}$ and $0.1 \mathrm{mg} \mathrm{P}^{-1}$. Therefore, the weighting factors were 1.46 $(=0.867 / 0.592)$ for $\mathrm{N}$ and $1.64(=0.0609 / 0.0372)$ for $\mathrm{P}$.

\subsubsection{Aggregated indicator and its evaluation}

The aggregated indicator (EII) values ranged from 0.9 to 81.1 in 1990 and 0.7 to 68.4 in 2005 (Figure 1a). Shizuoka had the highest EII value among prefectures. Aichi, Kagawa, Ehime, Nagasaki and Okinawa also had relatively high values compared to those of the other prefectures. Fukui had the lowest EII value, and Hokkaido, Niigata, Toyama and Ishikawa had relatively low values. The reasons underlying these rankings are unclear. The contribution of each impact differed widely among prefectures (Figure $1 \mathrm{~b}, \mathrm{c}$ ). In those prefectures with relatively high $E I I$ values, the contributions of $E N$ and $E P$ were dominant, except in Kagawa. In these prefectures, upland crops (including tea) and orchards distributed on 


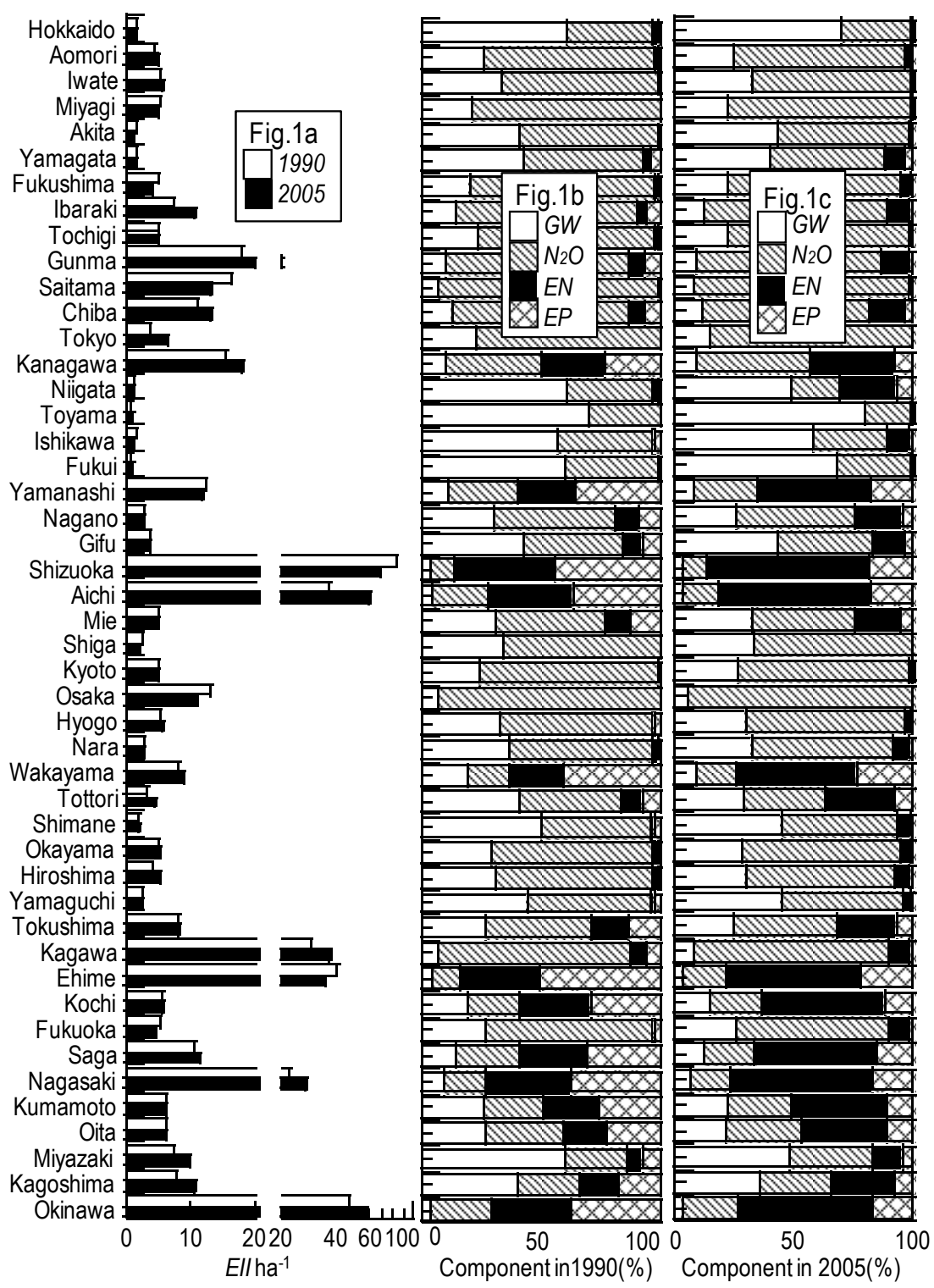

Figure 1: The environmental impact indicator $(E I I)$ values in each prefecture in 1990 and 2005 (a). The composition of environmental impacts as groundwater pollution potential $(G W)$, nitrous oxide emission $\left(\mathrm{N}_{2} \mathrm{O}\right)$ and surface (river) water eutrophication potential by $\mathrm{N}$ and $\mathrm{P}$ $(E N$ and $E P)$ in 1990 (b) and 2005 (c).

values, $G W$ and $\mathrm{N}_{2} \mathrm{O}$ emission were dominant factors, and these prefectures were dominated by paddy rice farming and extensive livestock farming. 
By comparing the EII value of each prefecture between 1990 and 2005, we found that the value increased in 26 prefectures and decreased in the other 21 prefectures. Although the reasons are unclear, we propose that prefectures with increased $E I I$ values increased the use of chemical $\mathrm{N}$ and $\mathrm{P}$ fertilizers and intensified livestock farming between 1990 and 2005. The relative contribution of $E P$ as compared to those of $E N, \mathrm{~N}_{2} \mathrm{O}$ emission and $G W$ decreased in 42 prefectures and increased in the other 5 . The main cause for this decrease was lower input of chemical $\mathrm{P}$ fertilizers [11], and the degree of reduction was larger than that of chemical $\mathrm{N}$ fertilizer input, which is the main cause of $\mathrm{N}$ surplus on farmland [2].

The Organization for Economic Co-operative Development (OECD) [12] proposed that the soil surface balance of $\mathrm{N}$ and $\mathrm{P}$ is a factor affecting air, water and soil damage. Mishima and Kohyama [2] reported that the highest $R N$ value that calculated by slight different to $\mathrm{N}$ surplus on soil surface balance $\mathrm{N}$ was observed in Miyazaki, followed by Shizuoka, Kagoshima and Okinawa. The high $R N$ values in Miyazaki and Kagoshima were caused by intensive livestock farming. However, these prefectures were not among those prefectures with extremely high EII values. The reasons for this discrepancy are the two prefectures' large precipitation, which lowers $G W$, and relatively little erosion potential, which lowers $E N$. Although both $R N$ and $E I I$ could indicate potential environmental impacts, we think that $R N$ would indicate just the whole absolute potential, whereas $E I I$ does not indicate the absolute potential of environmental impacts, but rather allows comparison of the relative degree of changes over time or among prefectures. The same idea could apply to $R P$ and $E I I$.

\subsection{Mitigation}

To mitigate N-related impacts, the agriculture sector should lower the input of chemical $\mathrm{N}$ fertilizer to crops, especially vegetables and tea [8], and apply restrictions on the intensity of livestock farming dependent on local land use [2], because $G W$ and $\mathrm{N}_{2} \mathrm{O}$ emission depend on the amount of $\mathrm{N}$ flow. Although $E N$ is related to $R N$ as well as the available $\mathrm{N}$ in farmland soil, $E N$ is significantly correlated with $R N$ :

$$
E N=\left(-6.22 \times 10^{6}\right)+\left(7.02 \times 10^{5} \times R N\right)(r=0.723, p<0.001)
$$

Therefore, the regulation of $\mathrm{N}$ flow would be a sound mitigation measure for N-related impacts.

However, $R P$ is not correlated with $E P$; rather $E P$ is strongly affected by available $P$ in farmland soil. Because soil testing in recent years has revealed increased and sometimes excessive levels of $\mathrm{P}$ [13], $\mathrm{P}$ fertilization should be performed dependent on the actual $\mathrm{P}$ fertility of farmland soil. Thus, to mitigate $E P, \mathrm{P}$ fertilization should be more tightly regulated. 


\section{Conclusion}

The aim of this study was to gain a basic understanding of the environmental impacts of agricultural production in Japan between 1990 and 2005. The absolute value of EII does not indicate the potential environmental impacts; rather it allows comparison of the relative degree of change over time and the differences among prefectures. In general, the $E I I$ value is based on the potential environmental impacts due to fertilizer use, except $\mathrm{N}_{2} \mathrm{O}$ emission, which was based on the IPCC's official estimation methodology. Therefore, our conclusions based on EII values may differ from those based on other indicators, such as $\mathrm{N}$ and $\mathrm{P}$ surpluses, which are utilized by the OECD to determine potential environmental impacts. Although we cannot judge which indicator is better for evaluating regional environmental impacts, the EII is easier to use in the EcoBalance model for compromising economy and environmental impacts, because this indicator simplifies the number of impacts that must be considered.

\section{References}

[1] Seppälä, J. \& Hämäläinen, R.P., On the meaning of the distance-to-target weighting method and normalisation in life cycle impact assessment. International Journal of Life Cycle Assessment, 6(4), pp. 211-218, 2001.

[2] Mishima, S. \& Kohyama, K., The database and the methodologies to estimate recent trend of nitrogen $(\mathrm{N})$ and phosphate $(\mathrm{P})$ flows and residual $\mathrm{N}$ and $\mathrm{P}$ in Japanese national prefectural scales and examples their application. Bulletin of National Institute for Agro-Environmental Sciences, 27, pp. 117-139, 2010.

[3] MAFF, Soil Environment Basic Research: Fixed Point Survey, MAFF: Tokyo, p.236\& p.465, 2008 (In Japanese).

[4] IPCC, IPCC Guidelines for National Greenhouse Gas Inventory. Vol. 4, Agriculture, Forestry and Other Land Use, IPCC: Hayama, pp. 10.52-11.25, 2006.

[5] Mishima, S., Endo, A. \& Kohyama, K., Recent trend in residual nitrogen on national and regional scales in Japan and its relation with groundwater quality. Nutrient Cycling in Agroecosystems, 83(1), pp. 1-11, 2009.

[6] Japan River Association, Japan River Water Quality Yearbook, Ministry of Land, Infrastructure, Transport and Tourism: Tokyo, CD-ROM, 2005.

[7] Brentrup, F., Küsters, J., Kuhlmann, H. \& Lammel, J., Environmental impact assessment of agricultural production systems using the life cycle assessment methodology. I. Theoretical concept of a LCA method tailored to crop production. European Journal of Agronomy, 20, pp. 247-264, 2004.

[8] Mishima, S., Endo, A. \& Kohyama, K., Nitrogen and phosphate balance on crop production in Japan on national and prefectural scales. Nutrient Cycling in Agroecosystems, 87(2), pp. 159-173, 2010.

[9] Akiyama, H., Yan, X. \& Yagi, K., Estimations of emission factors for fertilizer-induced direct $\mathrm{N}_{2} \mathrm{O}$ emissions from agricultural soils in Japan: 
summary of available data. Soil Science and Plant Nutrition, 52, pp. 774-787, 2006.

[10] Kumazawa, K., Present state of nitrate pollution in groundwater. Japanese Journal of Soil Science and Plant Nutrition, 70(2), pp. 207-213, 1999 (in Japanese with English summary).

[11] Mishima, S., Endo, A. \& Kohyama, K. Recent trends in phosphate balance nationally and by region in Japan. Nutrient Cycling in Agroecosystems, 86(1), pp. 69-77, 2010.

[12] OECD, Nutrients. Environmental Performance of Agriculture in OECD Countries since 1990, OECD: Paris, pp. 48-62, 2008.

[13] Obara, H., Outline of the soil monitoring and soil quality changes of the arable land in Japan. Pedologist, 44, pp. 134-142, 2000 (in Japanese with English summary). 